\title{
Regulation of mTOR function in response to hypoxia by REDD1 and the TSC1/TSC2 tumor suppressor complex
}

\author{
James Brugarolas, ${ }^{1}$ Kui Lei, ${ }^{2}$ Rebecca L. Hurley, ${ }^{3}$ Brendan D. Manning, ${ }^{4}$ Jan H. Reiling, ${ }^{5}$ \\ Ernst Hafen, ${ }^{5}$ Lee A. Witters, ${ }^{3}$ Leif W. Ellisen, ${ }^{2}$ and William G. Kaelin Jr. ${ }^{1,6,7}$ \\ ${ }^{1}$ Dana-Farber Cancer Institute and Brigham and Women's Hospital, Harvard Medical School, Boston, Massachusetts 02115, \\ USA; ${ }^{2}$ Massachusetts General Hospital Cancer Center, Harvard Medical School, Boston, Massachusetts 02116, USA; \\ ${ }^{3}$ Departments of Medicine and Biochemistry, Dartmouth Medical School and Department of Biological Sciences, Dartmouth \\ College, Hanover, New Hampshire 03755, USA; ${ }^{4}$ Department of Genetics \& Complex Diseases, Harvard School of Public \\ Health, Boston, Massachusetts 02115, USA; ${ }^{5}$ Zoologisches Institut, Universitaet Zuerich, Winterthurerstr. 190, CH-8057 \\ Zuerich, Switzerland; ${ }^{6}$ Howard Hughes Medical Institute, Chevy Chase, Maryland 20815, USA
}

\begin{abstract}
Mammalian target of rapamycin (mTOR) is a central regulator of protein synthesis whose activity is modulated by a variety of signals. Energy depletion and hypoxia result in mTOR inhibition. While energy depletion inhibits mTOR through a process involving the activation of AMP-activated protein kinase (AMPK) by LKB1 and subsequent phosphorylation of TSC2, the mechanism of mTOR inhibition by hypoxia is not known. Here we show that mTOR inhibition by hypoxia requires the TSC1/TSC2 tumor suppressor complex and the hypoxia-inducible gene REDD1/RTP801. Disruption of the TSC1/TSC2 complex through loss of TSC1 or TSC2 blocks the effects of hypoxia on mTOR, as measured by changes in the mTOR targets S6K and 4E-BP1, and results in abnormal accumulation of Hypoxia-inducible factor (HIF). In contrast to energy depletion, mTOR inhibition by hypoxia does not require AMPK or LKB1. Down-regulation of mTOR activity by hypoxia requires de novo mRNA synthesis and correlates with increased expression of the hypoxia-inducible REDD1 gene. Disruption of REDD1 abrogates the hypoxia-induced inhibition of mTOR, and REDD1 overexpression is sufficient to down-regulate S6K phosphorylation in a TSC1/TSC2-dependent manner. Inhibition of mTOR function by hypoxia is likely to be important for tumor suppression as TSC2-deficient cells maintain abnormally high levels of cell proliferation under hypoxia.
\end{abstract}

[Keywords: Tuberous Sclerosis Complex; TSC1; TSC2; REDD1/RTP801; mTOR; Hypoxia]

Supplemental material is available at http://www.genesdev.org.

Received August 31, 2004; revised version accepted October 6, 2004.

Tuberous sclerosis complex, a disease characterized by benign tumors in multiple tissues, results from mutations in either Tuberous Sclerosis Complex 1 (Tsc1) or 2 (Tsc2) (Cheadle et al. 2000). Tsc1 (also called hamartin) and Tsc2 (also called tuberin) form a protein complex (van Slegtenhorst et al. 1998) that integrates signals from a variety of sources, including growth factors (Gao and Pan 2001; Potter et al. 2001; Tapon et al. 2001) and energy stores (Inoki et al. 2003b), with the protein translation apparatus. Tsc2 functions as a GTPase-activating protein (GAP) toward the small $\mathrm{G}$ protein Rheb, which through a poorly understood mechanism controls mam-

${ }^{7}$ Corresponding author.

E-MAIL william_kaelin@dfci.harvard.edu; FAX (617) 632-4760. Article published online ahead of print. Article and publication date are at http://www.genesdev.org/cgi/doi/10.1101/gad.1256804. malian target of rapamycin (mTOR), a central regulator of protein translation (Castro et al. 2003; Garami et al. 2003; Inoki et al. 2003a; Saucedo et al. 2003; Stocker et al. 2003; Tee et al. 2003; Y. Zhang et al. 2003).

Regulation of mTOR by growth factors has been intensively studied. In response to growth factor stimulation, phosphatidylinositol 3-kinase (PI3K) is activated, leading to the generation of phosphatidylinositol-3,4,5triphosphate and the recruitment of Akt to the plasma membrane where it is activated by phosphorylation (Cantley 2002). Akt is a serine/threonine kinase that phosphorylates many effectors including Tsc2 (Dan et al. 2002; Inoki et al. 2002; Manning et al. 2002; Potter et al. 2002). The mechanism whereby Akt phosphorylation regulates Tsc2 function is controversial, but it is thought ultimately to lead to its inactivation, thereby allowing the accumulation of Rheb-GTP and the activation of 
mTOR. In support of the idea that Tsc1/Tsc 2 plays a critical role in $\mathrm{mTOR}$ regulation by growth factors, cells deficient for Tsc1 or Tsc2 fail to down-regulate mTOR function in response to growth factor deprivation (Gao et al. 2002; Inoki et al. 2002; Jaeschke et al. 2002; Kwiatkowski et al. 2002; H. Zhang et al. 2003).

Recent studies have also shed light on how Tsc1/Tsc2 regulates $\mathrm{mTOR}$ function in response to changes in energy availability. AMP-activated protein kinase (AMPK) is a master regulator of energy metabolism that is activated in response to energy deprivation (Carling 2004). AMPK functions as a serine/threonine kinase and directly phosphorylates Tsc2 (Inoki et al. 2003b). Cells deficient for Tsc1/Tsc2, or producing a TSC2 variant that can not be phosphorylated by AMPK, fail to down-regulate $\mathrm{mTOR}$ in situations of energy deprivation (Inoki et al. 2003b). Signaling by energy depletion also involves the Lkb1 tumor suppressor protein, which is inactivated in Peutz-Jeghers syndrome. Lkb1 is a serine/threonine kinase that phosphorylates a variety of substrates, including AMPK (Hawley et al. 2003; Woods et al. 2003; Shaw et al. 2004b). AMPK activation with consequent Tsc1/Tsc2-mediated inhibition of mTOR by energy depletion requires Lkb1 (Corradetti et al. 2004; Shaw et al. 2004b). Thus under conditions that are adverse for growth, such as in the presence of reduced energy stores, mTOR function is inhibited, thereby down-regulating protein synthesis and conserving energy.

mTOR function is also regulated by amino acid availability (Gingras et al. 2001). Whereas mTOR regulation by growth factors and energy stores requires an intact Tsc1/Tsc2 complex, amino acids seem to regulate mTOR function through both Tsc1/Tsc2-dependent and independent pathways (Gao et al. 2002; H. Zhang et al. 2003).

$\mathrm{mTOR}$ is a conserved serine/threonine kinase that phosphorylates a series of substrates involved in protein translation including 4E-BP1 and S6K /Gingras et al. 2001). 4E-BP1 binds the translation initiation factor eIF$4 \mathrm{E}$, preventing its interaction with other members of the eIF-4 complex and thereby inhibiting translation initiation of $5^{\prime}$ cap (7-methyl GTP) mRNAs. 4E-BP1 phosphorylation by mTOR, as well as other kinases in the PI3K pathway, relieves this inhibition, thereby promoting mRNA translation (Gingras et al. 2001).

In mammals, there are two $S 6 K$ genes, S6K1 and S6K2, and each has two different splice forms. While S6K2 and the long form $(\sim 85 \mathrm{kDa})$ of S6K1 localize to the nucleus, the short form of $\mathrm{S} 6 \mathrm{~K} 1(\sim 70 \mathrm{kDa})$ is cytoplasmic. $\mathrm{S} 6 \mathrm{~K}$ is thought to exist in an inactive, closed conformation, resulting from an intramolecular interaction between the catalytic domain and a pseudosubstrate domain (Fingar and Blenis 2004). There are at least eight phosphorylation sites in S6K1 and its activation requires a complex process of phosphorylation involving mTOR as well as other PI3K effectors. Phosphorylation in the linker region, at Ser 371 and Thr 389, is essential for S6K1 activation (Dufner and Thomas 1999). Thr 389 is the major rapamycin-sensitive site and can be phosphorylated by mTOR in vitro, suggesting that it is a direct mTOR tar- get (Dufner and Thomas 1999). Phosphorylation at this site has also been shown to be regulated in response to changes in Tsc1/Tsc2 levels (Inoki et al. 2002; Jaeschke et al. 2002; Kwiatkowski et al. 2002; Manning et al. 2002; H. Zhang et al. 2003).

The best-characterized substrate of S6K1 is the ribosomal protein S6. S6 is an integral component of the 40S subunit that is required for cell proliferation but whose precise function is unclear (Volarevic et al. 2000). S6 is thought to be regulated primarily through successive phosphorylation events beginning at S236 and S235. Phosphorylation at these sites is rapamycin-sensitive and largely mediated by S6K (Dufner and Thomas 1999). Indeed, cells deficient for both S6K1 and S6K2 have profoundly reduced levels of S6 S235/236 phosphorylation (Pende et al. 2004). Thus, S235/236 phosphorylation provides an accurate readout for endogenous S6K activity.

The Hypoxia-inducible factor (Hif) has also been shown to be regulated by mTOR (Hudson et al. 2002). Hif is a heterodimeric transcription factor composed of a stable $\beta$ and a labile $\alpha$ subunit whose levels are controlled by oxygen tension (Semenza 2000). In the presence of oxygen, Hif- $\alpha$ subunits are hydroxylated at specific prolyl residues and targeted for degradation by an E3 ubiquitin ligase that contains the von Hippel-Lindau tumor suppressor protein (pVHL) (Kaelin 2002). pVHL inactivation in patients with von Hippel-Lindau disease results in Hif up-regulation and the development of tumors. As in pVHL-deficient cells, Tsc2-deficient cells harbor increased levels of Hif- $\alpha$ relative to wild-type cells, especially under growth factor poor conditions (Brugarolas et al. 2003). Hif up-regulation in Tsc2-deficient cells is likely to result from increased mTOR activity as mTOR increases Hif stability and increased Hif levels in Tsc2-deficient cells can be normalized by treatment with rapamycin (Hudson et al. 2002; Brugarolas et al. 2003).

It was recently shown that mTOR function is regulated by hypoxia (Arsham et al. 2003). Hypoxia downregulates 4E-BP1 phosphorylation and increases 4E-BP1 binding to eIF-4E at $5^{\prime}$ cap structures. Similarly, hypoxia down-regulates S6K phosphorylation at multiple sites including T389 and inhibits S6 phosphorylation. Hypoxia-induced inhibition of $\mathrm{mTOR}$ is dominant over mTOR activating signals from growth factors and nutrients and occurs independently of Hif- $1 \alpha$ (Arsham et al. 2003). However, how mTOR function is regulated by hypoxia is not known.

Here we show that mTOR inhibition by hypoxia requires an intact Tsc1/Tsc2 complex. Furthermore, down-regulation of mTOR function by hypoxia requires de novo transcription and the expression of the hypoxiainducible Redd1/RTP801 gene.

\section{Results}

Tsc1/Tsc2 complex is required for mTOR regulation by hypoxia

To examine the contribution of the Tsc1/Tsc2 complex to the regulation of $\mathrm{mTOR}$ function by hypoxia, the ef- 
fects of hypoxia on MEFs derived from Tsc2-deficient embryos were analyzed. Loss of Tsc 2 results in lethality at approximately day 10.5 of gestation when it is difficult to obtain a large number of fibroblasts (Rennebeck et al. 1998). To extend the life span of the few fibroblasts that can be obtained from these embryos, mice were intercrossed with mice carrying mutations in $p 53$, which enhances the life span of the limited number of MEFs that can be obtained ( $\mathrm{H}$. Zhang et al. 2003). In the experiments that follow, Tsc2 ${ }^{-/-} ; p 53^{-/-}$MEFs were compared with $T s c 2^{+/+}{ }_{i} p 53^{-/-}$MEFs. For simplicity, these MEFs are referred to as "Tsc2 $2^{-/-\prime}$ and "Tsc2 ${ }^{+/+}$," respectively.

Tsc1/Tsc2 complex regulates $\mathrm{mTOR}$ in response to growth factors. As shown before, serum deprivation inhibits mTOR, as evidenced by decreased phosphorylation of the mTOR effector S6K (T389) (Fig. 1A). S6K T389 is the major rapamycin-sensitive site and is required for S6K activity (Dufner and Thomas 1999). The down-regulation of S6K phosphorylation is associated with a decrease in S6 phosphorylation (S235/236). We also confirmed that mTOR inhibition by serum deprivation requires an intact Tsc1/Tsc2 complex and is abrogated in Tsc2 $^{-/-}$MEFs (Fig. 1A) (Jaeschke et al. 2002; H. Zhang et al. 2003). Rapamycin inhibits S6K phosphorylation and activity regardless of Tsc2 status, supporting the concept that Tsc1/Tsc2 functions upstream of mTOR (Fig. 1A).

$\mathrm{TsC2}^{+/+}$MEFs down-regulated S6K phosphorylation and activity in response to hypoxia (Fig. 1A), in keeping with an earlier study using transformed human embryonic kidney (HEK293) cells (Arsham et al. 2003). Downregulation of $\mathrm{S} 6$ phosphorylation in response to hypoxia was also demonstrable in mice exposed to $6 \%$ oxygen, suggesting that this phenomenon is not restricted to tissue culture (Supplementary Fig. 1). In contrast, hypoxia failed to down-regulate $\mathrm{S} 6 \mathrm{~K}$ and $\mathrm{S} 6$ phosphorylation in $\mathrm{Tsc}^{-/-}$MEFs (Fig. 1A) and $\mathrm{Tsc1}^{-/-}$mouse $3 \mathrm{~T} 3$ cells (Fig. 1B), indicating that mTOR inhibition by hypoxia requires an intact $T s c 1 / T s c 2$ complex. Likewise hypoxia promoted the binding of 4E-BP1 to 7-methyl GTP $(7 \mathrm{mGTP})$ in $\mathrm{Tsc}^{+/+}$cells but not $\mathrm{Tsc}^{-/-}$cells, consistent with Tsc2-dependent inhibition of 4E-BP1 phosphorylation by mTOR in response to hypoxia (Fig. 1C). Taken together, these data indicate that mTOR inhibition by hypoxia requires a functional Tsc1/Tsc2 complex.

We previously showed that Hif- $\alpha$ (hereafter referred to as Hif) levels are regulated in response to growth factors through a mechanism that involves the Tsc1/Tsc2 complex and mTOR (Brugarolas et al. 2003; see also Fig. 1A). As Tsc2 $2^{-1-}$ MEFs failed to down-regulate mTOR activity in response to hypoxia, we postulated that Hif levels might also be affected. Tsc2 ${ }^{-/-}$MEFs were not impaired in the up-regulation of Hif in response to hypoxia. However, whereas $\mathrm{Tsc2}^{+/+}$MEFs down-regulated Hif with prolonged hypoxia, Hif levels remained elevated in Tsc2 $2^{-/-}$MEFs (Fig. 1D). Consistent with the idea that increased Hif levels in Tsc2 $2^{-/}$cells under prolonged hypoxia result from increased mTOR activity, treatment

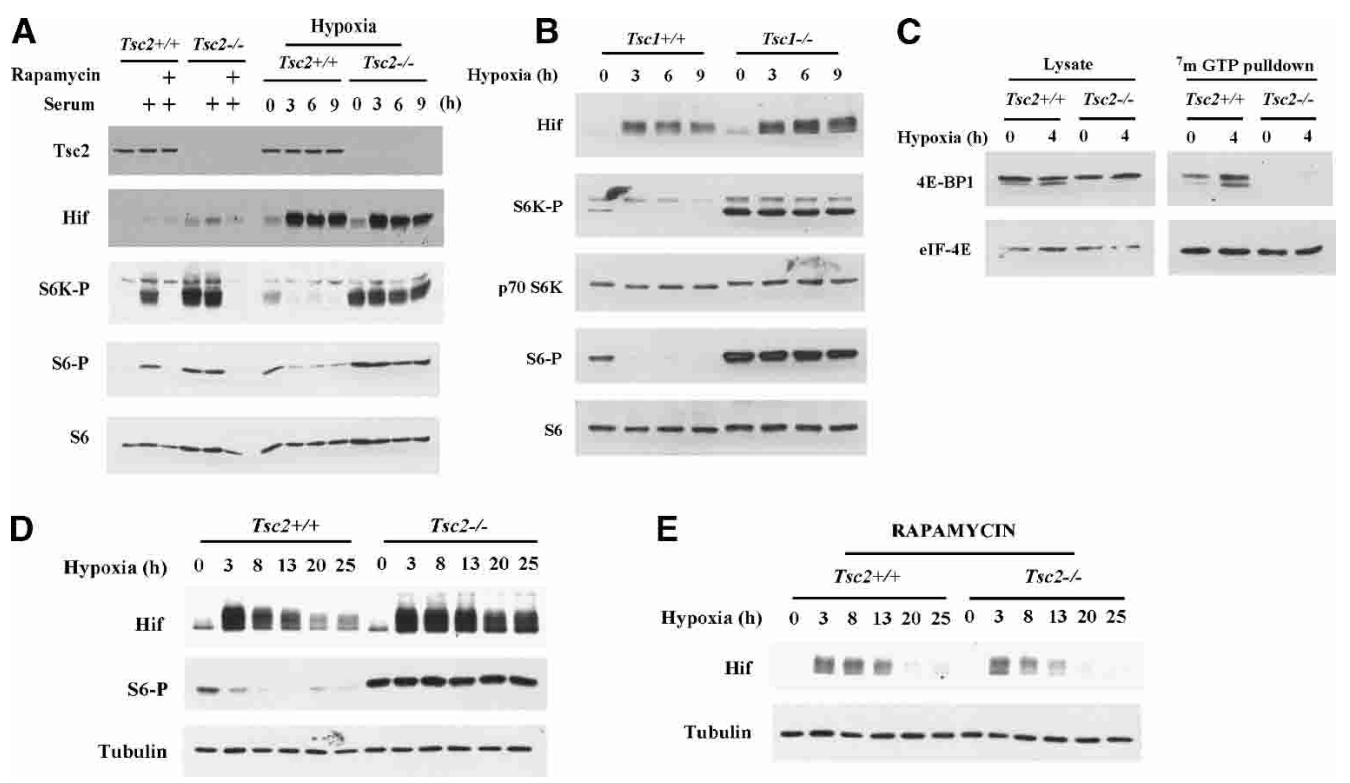

Figure 1. Tsc2 regulates mTOR in response to hypoxia. (A) Western blot analysis of Tsc2 ${ }^{+/+}$and Tsc2 ${ }^{-/-}$MEFs. (Hif) Hif- $1 \alpha$ and/or Hif- $2 \alpha$; (S6K-P) S6K phosphorylated T389; (S6-P) S6 phosphorylated on S235/236. Left panel shows MEF in 0.05\% serum or following serum addition ( $10 \%$ serum for $45 \mathrm{~min}$ ) pretreated or not with rapamycin (1.5 h prior to serum addition). Right panel shows MEFs exposed to hypoxia for the indicated periods of time. $(B)$ Western blot analysis of $\mathrm{Tsc1}^{+/+}$and Tsc1 $1^{-/-}$mouse $3 \mathrm{~T} 3$ cells treated with hypoxia for the indicated periods of time. $(C)$ Western blot analysis of input (left) and ${ }^{7} \mathrm{mGTP}$-bound (right) proteins from extracts of $\mathrm{TsC2}^{+/+}$and $T s c 2^{-/-}$MEFs exposed to hypoxia for the indicated periods of time. $(D, E)$ Western blot analysis of extracts from Tsc2 $2^{+/+}$and $\mathrm{Tsc}^{-/-} \mathrm{MEFs}$ exposed to hypoxia for the indicated periods of time. In $E$ all the cells were treated with rapamycin for $26 \mathrm{~h}$ prior to lysis regardless of the duration of hypoxia. 
with rapamycin restored the down-regulation of Hif normally observed after prolonged hypoxia (Fig. 1E).

The importance of Tsc2 in the regulation of mTOR by hypoxia is further supported by reconstitution experiments. Tsc2 $2^{-/-}$MEFs were infected with a retrovirus encoding epitope-tagged human Tsc2. Retrovirally transduced Tsc2 $2^{-/}$MEFs achieved Tsc2 protein levels that were similar to endogenous levels in $\mathrm{Tsc}^{+/+}$MEFs (Fig. 2A). Reintroduction of Tsc2 into $\mathrm{Tsc}^{-/-} \mathrm{MEFs}$ restored the down-regulation of S6 phosphorylation by hypoxia (Fig. 2A).

To determine the generalizability of our observations, the role of $\mathrm{Tsc} 2$ in $\mathrm{mTOR}$ regulation by hypoxia was examined in other cell types. Tsc2 knockdown with two different Tsc2 siRNAs in HEK293 and HeLa cervical carcinoma cells blocked the down-regulation of S6 phosphorylation by hypoxia (Fig. 2B; Supplementary Fig. 2), indicating that Tsc 2 is required for $\mathrm{mTOR}$ regulation by hypoxia in multiple cell types.

\section{Tsc2 inactivation confers a proliferative advantage under hypoxia}

Taken together, these data establish the importance of Tsc1/Tsc2 in the regulation of $\mathrm{mTOR}$ by hypoxia. As Tsc1/Tsc2 functions as a tumor suppressor, we asked whether disruption of this complex would affect cell proliferation under hypoxic conditions. In keeping with previous observations, the rates of cell proliferation of

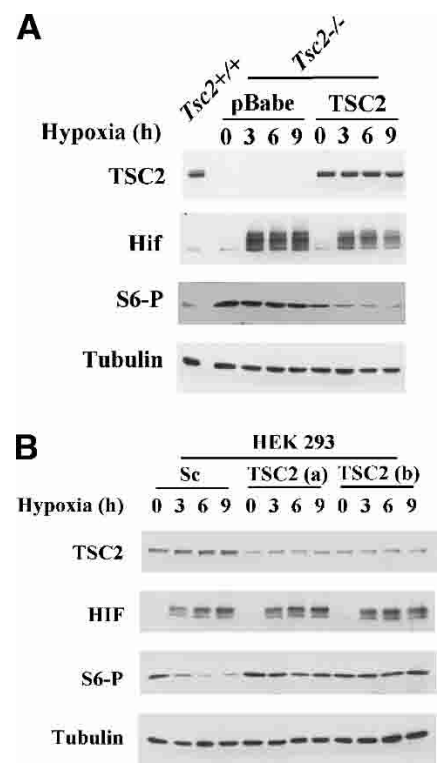

Figure 2. Tsc2 is both necessary and sufficient for the regulation of $\mathrm{S} 6$ phosphorylation by hypoxia. (A) Western blot analysis of $\mathrm{Tsc}^{-/-}$MEFs retrovirally transduced with either a Tsc2 expression vector or an empty vector and treated with hypoxia for the indicated periods of time. $\mathrm{Tsc}^{+/+} \mathrm{MEFs}$ are included as controls. (B) Western blot analysis of HEK293 cells transfected with two different synthetic Tsc2 siRNAs (a and b) or a scrambled siRNA ( $\mathrm{Sc}$ ) and exposed to hypoxia for the indicated periods of time.
$\mathrm{Tsc}^{-/-}$and $\mathrm{Tsc2}^{+/+}$MEFs were very similar under normoxic conditions for several days (Fig. 3A; H. Zhang et al. 2003). After $4 \mathrm{~d}$ in culture the rate of proliferation of $\mathrm{Tsc}^{+/+}$cells began to decline relative to $T s c 2^{-/-}$cells, possibly due to depletion of nutrients and growth factors from the media. Consistent with this idea, $T s c 2^{-/-}$but not $\mathrm{Tsc}^{+/+}$MEFs proliferate under conditions of serum deprivation (H. Zhang et al. 2003). We next measured the proliferation of $\mathrm{Tsc}^{-/-}$and $T s c 2^{+/+}$cells under hypoxic conditions. To avoid confounding effects from media depletion, the media was changed daily. Under hypoxic conditions $\mathrm{Tsc}^{-/-}$MEFs exhibited a marked proliferative advantage compared with $T s c 2^{+/+}$MEFs (Fig. 3B). Increased proliferation of $\mathrm{Tsc}^{-/-} \mathrm{MEFs}$ under hypoxic conditions correlated with persistently elevated levels of S6 phosphorylation (Fig. 3C) and was abrogated by treatment with rapamycin (Fig. 3B). These data suggest that failure to down-regulate $\mathrm{mTOR}$ in response to hypoxia in $T s c 2^{-/-}$MEFs confers a growth advantage that might contribute to tumor formation in TSC patients. It should be noted that the growth inhibitory effect of hypoxia on $\mathrm{Tsc}^{+/+}$MEFs in these assays is p53 independent since both the $\mathrm{Tsc}^{+/+}$and $\mathrm{Tsc2}^{-/-}$MEFs used here lack p53.

\section{Tsc1/Tsc2 regulation by hypoxia is $A M P K$ and $\mathrm{Lkb1}$ independent}

Energy depletion results in Tsc1/Tsc2-mediated mTOR inhibition through a mechanism that involves Lkb1 and AMPK (Inoki et al. 2003b; Corradetti et al. 2004; Shaw et al. 2004a). Since hypoxia might also affect cellular energy stores, we sought to determine whether hypoxia regulated mTOR through a similar pathway. AICAR (5aminoomidazole-4-carboxyamide), a cell-permeable AMPK agonist, inhibited mTOR and down-regulated S6 phosphorylation (Fig. 4A; Kimura et al. 2003). As previously reported (Shaw et al. 2004b), Tsc2 ${ }^{-/-}$cells failed to down-regulate $\mathrm{S} 6$ phosphorylation in response to AICAR despite robust activation of AMPK as determined by AMPK phosphorylation in the T loop and the phosphorylation of its substrate acetyl-CoA carboxylase (ACC) (Fig. 4A), thereby justifying the use of AICAR as an AMPK perturbant in the experiments described below.

To ask whether hypoxia signals are transduced through an energy depletion pathway in our system, we first examined the effects of hypoxia on AMPK activity. After $4 \mathrm{~h}$ of hypoxia, S6 phosphorylation was markedly down-regulated without a detectable increase in AMPK activity, as measured by ACC phosphorylation (Fig. 4B). The ability to detect ACC phosphorylation in response to AMPK activation was confirmed by studying cells treated with AICAR in parallel (Fig. 4B). Furthermore, in vitro kinase assays with AMPK immunoprecipitates from the same lysates used for Figure $4 \mathrm{~B}$ indicated that hypoxia, in contrast to AICAR, did not increase and may have decreased AMPK kinase activity (Fig. 4C). These results are consistent with a recent study of HEK293 cells exposed to hypoxia for $30 \mathrm{~min}$ (Arsham et al. 2003).

We next asked whether AMPK activity is necessary for 

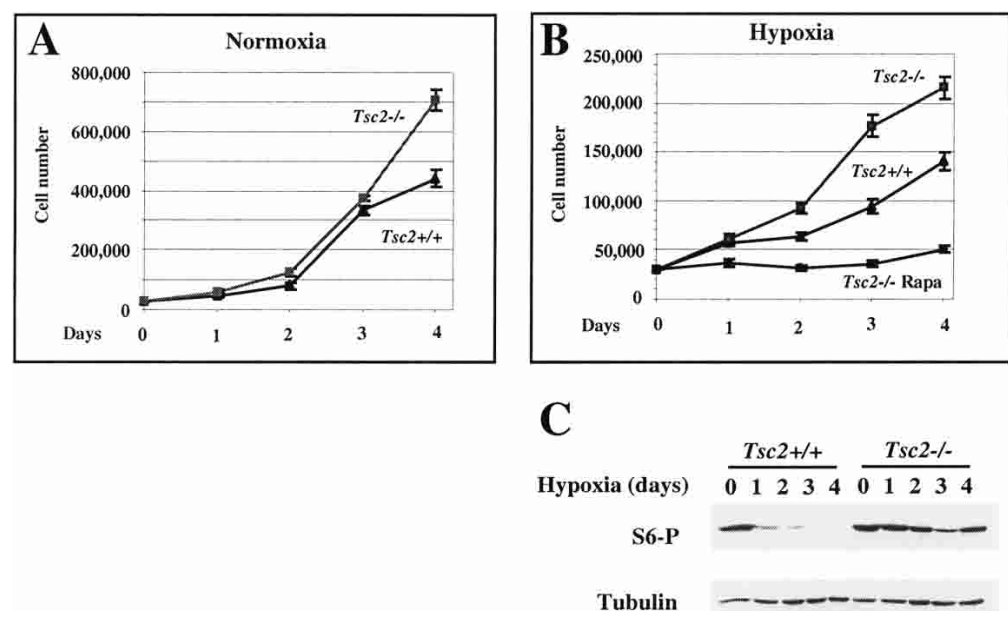

Figure 3. Tsc2 loss confers a proliferative advantage under hypoxic conditions. (A) Proliferation rates of $\mathrm{Tsc}^{-{ }^{-}}$and $\mathrm{Tsc} 2^{+/+} \mathrm{MEFs}$ under normoxic conditions. (B) Proliferation rates under hypoxic conditions of $\mathrm{Tsc2}^{+/+}$and $\mathrm{Tsc2}^{-/-}$MEFs (treated or not with rapamycin). Error bars for $A$ and $B$ equal one standard deviation $(n=3)$. Note different $Y$-axis scales in $A$ and $B .(C)$ Western blot analysis of $\mathrm{TsC2}^{+/+}$and $\mathrm{TsC2}^{-/-}$MEFs cultured in parallel under hypoxic conditions for the indicated number of days. the hypoxia-induced down-regulation of mTOR function. Pharmacological inhibition of AMPK with compound C (Inoki et al. 2003b) at doses sufficient to block the down-regulation of S6 phosphorylation by AICAR did not block the down-regulation of S6 phosphorylation by hypoxia (Fig. 4D). Thus AMPK is required for AICAR signaling but not for hypoxia signaling.

Next we examined the requirements for the AMPK kinase Lkb1. Consistent with previous studies, $\mathrm{Lkb1}^{-/-}$ MEFs failed to down-regulate S6 phosphorylation in response to AICAR (Fig. 4E; Shaw et al. 2004b). In contrast, we found that Lkb1 loss did not affect the down-regulation of S6 phosphorylation by hypoxia (Fig. 4F). In addition, HeLa cells, which are defective for Lkb1 (Tiainen et al. 1999|, also down-regulated S6 phosphorylation in response to hypoxia but not to AICAR (Supplementary Fig. 3) indicating that Lkb1, like AMPK, is dispensable for hypoxia signaling. We noted, however, that ACC and AMPK do become phosphorylated in HeLa cells after prolonged hypoxia, possibly due to a non-Lkbl AMPK kinase (Supplementary Fig. 3). Nonetheless, inhibition of S6 phosphorylation occurred prior to appreciable AMPK activation in these cells, again in keeping with the idea that the acute down-regulation of mTOR in response to hypoxia is AMPK independent. It is possible that signaling to Tsc1/Tsc2 in response to chronic hypoxia involves both Lkbl/AMPK-dependent and independent pathways since prolonged hypoxia would predictably lead to ATP depletion and accumulation of AMP.

\section{Regulation of mTOR by hypoxia requires Redd1 induction}

To begin to unravel the signaling pathway whereby hypoxia regulates $\mathrm{Tsc} 1 / \mathrm{Tsc} 2$, we asked whether this mechanism required de novo transcription. Provocatively, inhibition of transcription with actinomycin D blocked the down-regulation of S6 phosphorylation by hypoxia, indicating that de novo transcription is necessary for hypoxia signaling (Fig. 5A). As a control actinomycin D alone did not affect baseline S6 phosphorylation (Fig. 5A).
Recently, the Drosophila ortholog of the hypoxia-inducible Redd1 gene was isolated in a screen for suppressors of insulin signaling (Reiling and Hafen 2004). Redd1 was originally identified by several groups as a gene that is induced at the mRNA level in response to stresses such as hypoxia or DNA damage (Ellisen et al. 2002; Shoshani et al. 2002). Redd1 encodes a protein with a predicted $\mathrm{MW}$ of $25 \mathrm{kDa}$ that lacks any known functional domains (Ellisen et al. 2002; Shoshani et al. 2002). Redd1 belongs to a family of highly conserved proteins that includes Redd2, which might also be regulated by hypoxia (Cuaz-Perolin et al. 2004). Redd orthologs have been shown to inhibit insulin signaling in Drosophila and epistasis analysis suggests that they act upstream of Tsc1/Tsc2 (Reiling and Hafen 2004).

To ascertain whether Redd1 was involved in the regulation of the mTOR by hypoxia, we first examined Redd1 induction in response to hypoxia in MEFs. Consistent with previous data, Redd1 mRNA levels were induced by hypoxia (Fig. 5B; Shoshani et al. 2002). Redd2 expression, however, was not detected in MEFs (data not shown).

To ask whether Reddl is necessary for hypoxia-induced down-regulation of mTOR function, we obtained Redd1 ${ }^{-/-}$MEFs (K. Lei and L.W. Ellisen, in prep.). In contrast to Redd1 $1^{+/+}$MEFs, Redd1 $1^{-/-}$MEFs failed to downregulate phosphorylation of S6K and S6 in response to hypoxia (Fig. 5C). These data indicate that Redd1, like Tsc1 and Tsc2, is necessary for the hypoxia-induced down-regulation of mTOR signaling. This requirement was specific because Redd1 $1^{-/-}$MEFs, in contrast to $\mathrm{Tsc2}^{-/-} \mathrm{MEFs}$, down-regulated $\mathrm{S} 6$ phosphorylation in response to serum deprivation (Fig. 6A,B). These data indicate that Reddl regulates mTOR signaling only in response to certain stimuli, such as hypoxia.

\section{Redd1 is sufficient to down-regulate S6K1 phosphorylation}

We next asked whether Redd 1 is sufficient to down-regulate mTOR function. For this purpose, the effects of Redd1 expression on S6K phosphorylation were determined. HEK293 cells were transfected with HA-tagged 
Brugarolas et al.

A

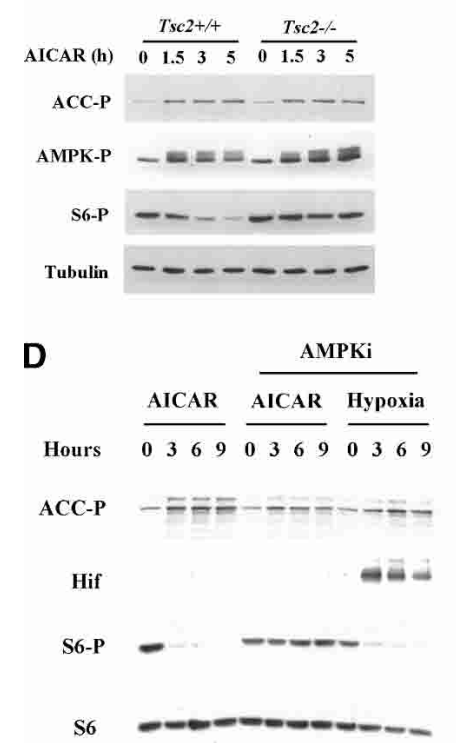

B

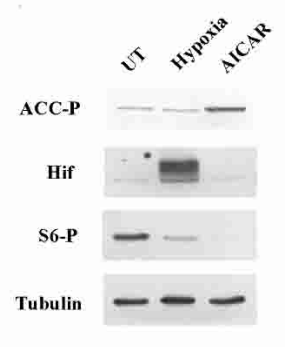

E
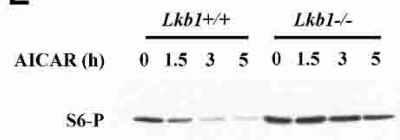

Tubulin

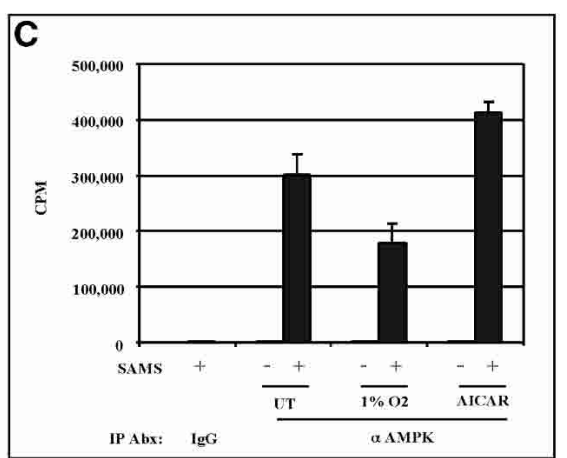

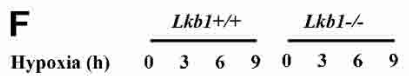

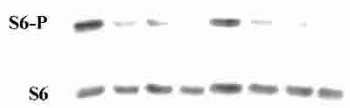

Figure 4. mTOR regulation by hypoxia is both AMPK and Lkb1 independent. $(A)$ Western blot analysis of extracts of Tsc2 $2^{++}$and $\mathrm{Tsc2}^{-/-}$MEFs treated with AICAR for the indicated periods of time. (ACC-P) Acetyl-CoA carboxylase phosphorylated at S79; (AMPK-P) AMPK phosphorylated at T172. (B) Western blot analysis of $T s c 2^{+/+}$MEFs after $4 \mathrm{~h}$ of treatment with either hypoxia or AICAR. (C) In vitro AMPK kinase assay of the same extracts used in $B$ immunoprecipitated in antibody excess with a polyclonal anti-AMPK $(\alpha$ AMPK) antibody or normal rabbit IgG (IgG). Samples were normalized for protein concentration prior to immunoprecipitation. Error bars equal one standard deviation $(n=3)$. Also shown are background activities of immunoprecipitates incubated in the absence of substrate (SAMS peptide). (D) Western blot analysis of $T s c 2^{+/+}$cells pretreated or not with the AMPK inhibitor compound C and exposed to either AICAR or hypoxia for the indicated periods of time. All cells treated with compound $\mathrm{C}$ were exposed to the drug for 9.5 h. $(E, F)$ Western blot of $L \mathrm{~kb}^{+/+}$or $L \mathrm{kb1}^{-/-}$MEFs treated with AICAR $(E)$ or hypoxia $(F)$ for the indicated periods of time.

human Redd1 (R1) or a mutant lacking its evolutionarily conserved central region $(\mathrm{R} 1 \mathrm{dC}$; amino acids $96-153$ out of 232). To exclude signal from untransfected cells, and thereby increase signal/noise ratio, a plasmid encoding HA-S6K1 (S6K) was included in the transfection mix. HA-S6K1 was then recovered by anti-HA immunoprecipitation and immunoblotted with an antibody specific for phospho-S6K1. Wild-type Redd1, but not mutant Redd1, down-regulated S6K1 phosphorylation (Fig. 7A). As a control, S6K1 phosphorylation was abrogated in cells treated with rapamycin (Fig. 7A). These data indicate that Redd1 is sufficient to down-regulate S6K1 phosphorylation and that this function requires the Redd1 central domain.

Simultaneous overexpression of two Redd orthologs in Drosophila, Scylla and Charybdis, results in additive effects with respect to cell size (Reiling and Hafen 2004). Since cell size in Drosophila is controlled by S6K, we asked whether Redd2 also down-regulated S6K1 phosphorylation. For this purpose, we repeated these experiments with HA-Redd2 (R2), alone or in combination with Redd1. Redd2, like Redd1, inhibited S6K1 phosphorylation and the effects of Redd1 and Redd 2 together were possibly additive (Fig. 7A). While the same epitope tag in Redd1 (or 2) and S6K1, combined with immunoprecipitation, could theoretically confound our results, qualitatively similar effects were observed when S6K1 phosphorylation was analyzed directly from cell lysates (data not shown).

\section{Down-regulation of S6K phosphorylation by Redd1 requires Tsc2}

To ask whether Redd1 functions upstream of Tsc2, similar assays were performed in HeLa cells in which Tsc2 function was impaired using siRNA. The effect of Redd1 and Redd2 on S6K1 phosphorylation in HeLa cells transfected with irrelevant siRNA (Sc; scrambled) mirrored those observed in HEK293 cells (Fig. 7, cf. B and A). In stark contrast, the effects of Redd1 and Redd2, alone or in combination, on S6K1 phosphorylation were completely abrogated in cells treated with either of two different Tsc2 siRNAs (a and b) (Fig. 7B).

To evaluate the effects of Redd1 on endogenous (rather than ectopic) S6K as well as S6 phosphorylation, and its dependency on Tsc1/Tsc2 for signaling, we generated a HA-Redd1-inducible cell line (Fig. 7C). These cells were transfected with siRNA (as above; Sc, Tsc2 a and b) and subsequently placed in media with tetracycline to induce HA-Redd1. Redd 1 induction resulted in a profound down-regulation of endogenous S6K and S6 phosphorylation unless Tsc2 was down-regulated by siRNA (Fig. 7C). Therefore down-regulation of S6K phosphorylation by Redd 1 and Redd 2 requires Tsc 2 . In addition, S6K 

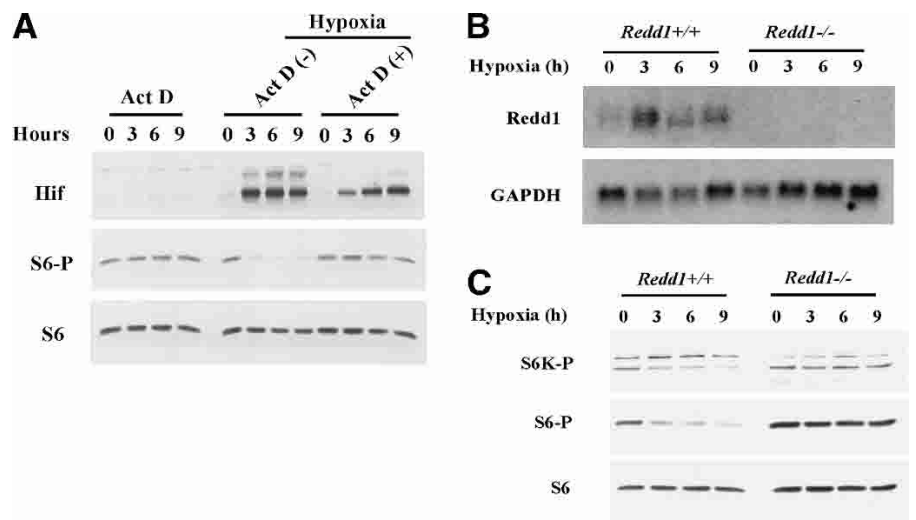

Figure 5. Down-regulation of mTOR function by hypoxia requires Redd1. (A) Western blot analysis of $\mathrm{Tsc2}^{+/+} \mathrm{MEFs}$ pretreated $30 \mathrm{~min}$ prior to initiation of the hypoxia time course) or not, with Actinomycin D and exposed to hypoxia for the indicated periods of time. Shown in parallel, analysis of $\mathrm{Tsc}^{+/+}$cells treated with Actinomycin D for the indicated periods of time. Northern blot $(B)$ and Western blot $(C)$ analysis of Redd1 $1^{++}$and Redd1 $1^{-/-}$MEFs treated with hypoxia for the indicated periods of time. phosphorylation in $R e d d 1^{-/-}$cells was down-regulated by treatment with rapamycin (data not shown), in keeping with the idea that Reddl acts upstream of mTOR. While we cannot formally exclude that Redd1 acts in a parallel pathway, our data suggest that Redd1 acts upstream of the Tsc1/Tsc2 complex to down-regulate mTOR function in response to hypoxia.

\section{Discussion}

The data presented here indicate that the down-regulation of mTOR function by hypoxia requires Tsc1/Tsc2. Under conditions of hypoxia, Tsc2-deficient cells fail to down-regulate S6K phosphorylation (and activity) and accumulate Hif abnormally. Disruption of the Tsc1/ Tsc2 complex results in increased cell proliferation under hypoxic conditions. Hypoxia signaling requires neither AMPK nor Lkbl but does require de novo transcription and the expression of Redd1. Redd1 is necessary and sufficient for the down-regulation of mTOR by hypoxia.

Our data reveal that mTOR regulation by hypoxia requires Tsc1/Tsc2 in multiple cell types. Tsc2 was essential for hypoxia-induced mTOR down-regulation in three

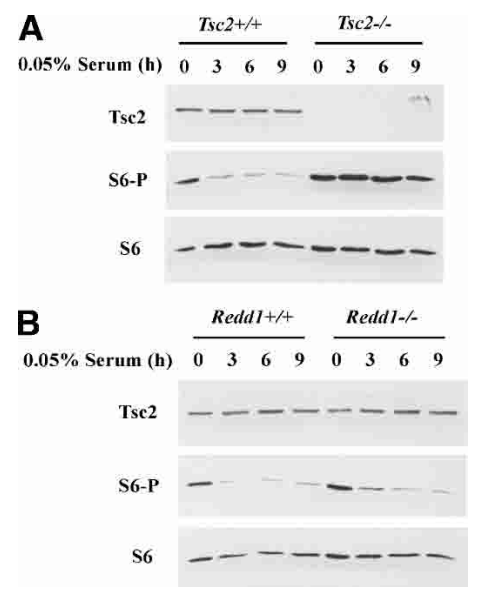

Figure 6. Tsc2 but not Redd1 is required for growth factor signaling. Western blot analysis of $T s c 2^{+/+}$and $T s c 2^{-/-} \operatorname{MEFs}(A)$ or Redd1 $1^{+/+}$and Redd1 $1^{-/-}$MEFs $(B)$ after serum deprivation for the indicated periods of time. different cell types, MEFs, HEK293 cells, and HeLa cells. The requirement of Tsc 2 for the down-regulation of mTOR in multiple diverse cell types suggests that mTOR regulation by hypoxia universally requires Tsc2. The regulation of mTOR function by hypoxia is likely to be important physiologically, as it occurs not only in cells grown in tissue culture, but also in vivo (Supplementary Fig. 1), and is likely impaired in tumors from TSC patients.

Exposure of Tsc2-deficient cells to hypoxia, in contrast to glucose (energy) depletion (Inoki et al. 2003b), did not result in a marked increase in cell death (determined by trypan blue exclusion; data not shown). Instead, our studies clearly demonstrate that loss of Tsc2, which functions as a tumor suppressor, confers a growth advantage to hypoxic cells. This phenomenon might contribute to the development of tumors in patients with tuberous sclerosis complex and lymphangioleiomyomatosis (LAM), which is also linked to Tsc2 mutations (Carsillo et al. 2000). Moreover, it raises the possibility that physiologically relevant levels of hypoxia in normal tissues, in a Tsc2-dependent manner, affect cell proliferation and the establishment of a post-mitotic state.

Tsc2 is involved in the down-regulation of Hif, especially under low serum conditions (Brugarolas et al. 2003) and, as shown here, in response to prolonged hypoxia. We and others have previously shown that increased Hif levels in Tsc2-deficient cells are associated with increased expression of Hif regulated genes including $V E G F-A$, which encodes for a potent angiogenic peptide (Nguyen-Vu et al. 2001; Brugarolas et al. 2003; El-Hashemite et al. 2003; Liu et al. 2003). Thus, prolonged hypoxia in Tsc2-deficient cells will further increase VEGF-A. Overproduction of VEGF-A almost certainly explains the angiogenic nature of neoplasms (hamartomas) observed in tuberous sclerosis complex disease and may play a causal role in LAM, which is a disease characterized by respiratory failure. The disease affects young women and arises from increased proliferation of smooth muscle and lymphatics in the lung parenchyma. While VEGF-A functions primarily on the blood vessel endothelium (Scavelli et al. 2004), it might also promote pulmonary lymphangiogenesis, thereby contributing to the pathogenesis of LAM. Increased pulmonary lymphangiogenesis would theoretically exacer- 
Figure 7. Down-regulation of S6K1 phosphorylation by Redd1 and Redd2. (A) Western blot analysis of anti-HA immunoprecipitates (top) or whole-cell extracts (bottom) from HEK293 cells transfected with HA-tagged expression vectors encoding Redd1 (R1), Redd1 mutant lacking central domain (R1dC), Redd2 (R2), Redd1 and Redd2 (R1 + R2), or an empty vector (pcDNA3). HA-S6K1 (S6K) was cotransfected where indicated. Rapamycin was added several hours prior to cell harvest where indicated. $(B)$ Western blot analysis of anti-HA immunoprecipitates (bottom) or whole-cell extracts (top) from HeLa cells exponentially growing under serum-rich conditions transfected with siRNAs (Sc, scrambled; Tsc2, b and a) and expression vectors as in $A$. Rapamycin was added several hours prior to cell harvest where indicated. $\operatorname{Ig}(\mathrm{H})$ indicates immunoglobulin heavy chain. (C) Western blot analysis of HA-Redd1 inducible U2OS cells transfected with the indicated siRNAs and stimulated to produce Redd1 with tetracycline for the indicated periods of time.
A
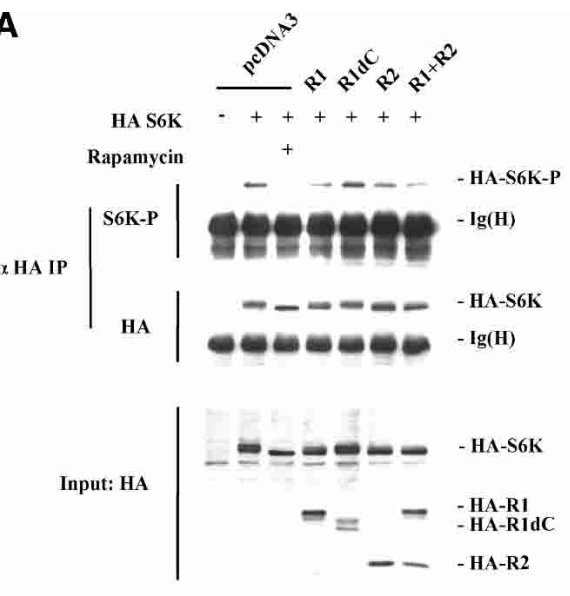

C

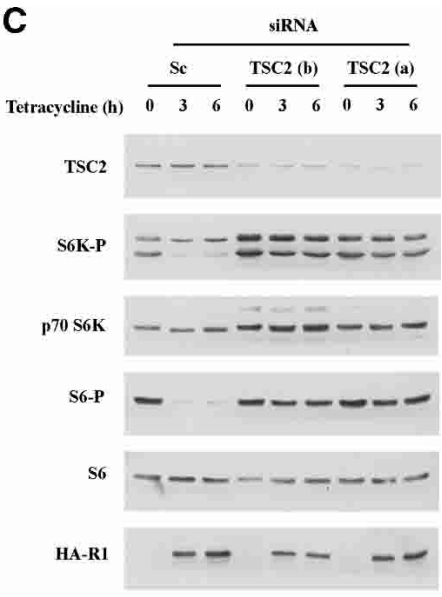

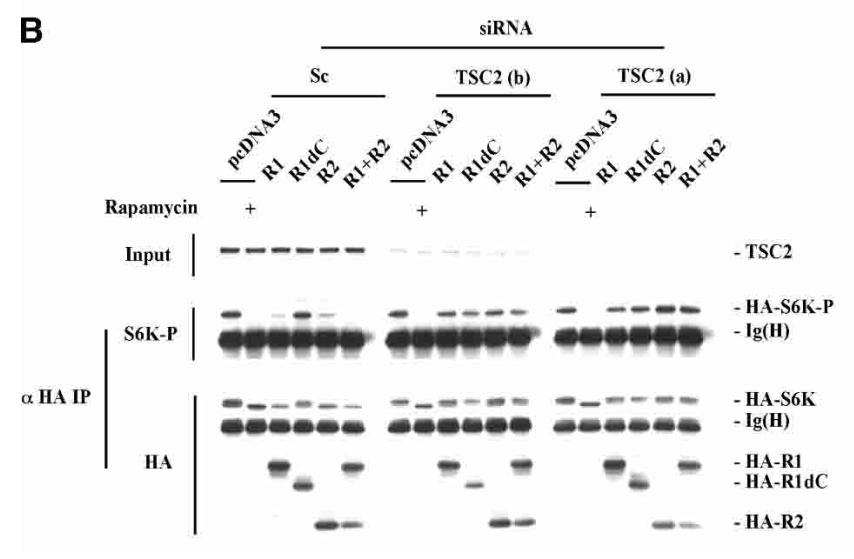

bate hypoxia and establish a vicious cycle characterized by increased Hif accumulation in Tsc2-deficient pulmonary cells, leading to increased VEGF-A and lymphangiogenesis.

In our assays, changes in the phosphorylation of S6 (S235/236) in response to hypoxia were more robust than changes in the phosphorylation of S6K (T389) or changes in the amount of 4E-BP1 bound to ${ }^{7}$ mGTP. While the importance of S6K in the phosphorylation of S6 is well documented (Pende et al. 2004), Tsc1/Tsc2 might conceivably also regulate $\mathbf{S 6}$ phosphorylation in an mTORindependent/S6K-independent manner. There is precedence for Tsc1/Tsc2 having rapamycin-insensitive, and hence probably mTOR-independent, activities (Brugarolas et al. 2003; Karbowniczek et al. 2004). The analysis of S6 phosphorylation is, however, biologically relevant, as S6 but not S6K (1 and 2) is essential for cell proliferation (Volarevic et al. 2000; Pende et al. 2004).

Our data indicate that hypoxia signaling to Tsc1/Tsc2 requires de novo transcription and the expression of the Redd1 gene. In keeping with published observations, we found that Redd1 mRNA is induced by hypoxia. The Redd1 gene contains a hypoxia response element in the promoter, which can be recognized by Hif- 1 complexes (Shoshani et al. 2002). On the other hand, Redd1 is also

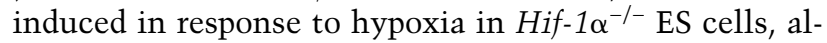
beit to a lesser extent (Shoshani et al. 2002). In addition,

Hif- $1 \alpha$ is dispensable for the down-regulation of mTOR in response to hypoxia (Arsham et al. 2003). These data suggest that induction of Redd1 by hypoxia can also be mediated by other Hif- $\alpha$ family members (such as Hif- $2 \alpha$ ) or perhaps by a Hif-independent mechanism.

Redd1 expression is sufficient to down-regulate S6K1 phosphorylation. This effect is abrogated by deleting the conserved central region of the protein (amino acids 96153) and requires Tsc2. While it cannot be excluded that Redd1 functions in a parallel pathway, the simplest model is that Redd1 functions upstream of, and activates, Tsc1/Tsc2, which in turn inhibits mTOR. Genetic experiments in Drosophila are consistent with this model (Reiling and Hafen 2004).

It will be important to determine how, mechanistically, Redd1 affects Tsc1/Tsc2 function. We have thus far been unable to detect complex formation between Tsc1/Tsc2 and Redd1 (J. Brugarolas, unpubl.). In theory, Redd1 might, at least indirectly, affect Tsc1/Tsc2 GAP activity. In pilot experiments, we confirmed that antiTsc2 immunoprecipitates from $\mathrm{Tsc2}^{+/+}$cells, but not from $T s c 2^{-/-}$cells, display Rheb GAP activity. However, no difference in GAP activity was found when Tsc2 immunoprecipitates from normoxic and hypoxic cells were compared (B. Manning and J. Brugarolas, unpubl.). These data suggest that either hypoxia does not alter the intrinsic GAP activity of Tsc2 or that this assay is not sensi- 
tive enough to pick up small, but physiologically relevant, changes in Tsc2 GAP activity.

While our data indicate that Tsc1/Tsc2 is necessary for the down-regulation of mTOR after prolonged hypoxia (several days; see Fig. 3C), it remains to be established whether Redd 1 is also required in this setting. Indeed the early peak in Redd1 expression in response to hypoxia suggests that Redd 1 might not play a role in $\mathrm{mTOR}$ regulation by chronic hypoxia. It is also possible that AMPK and Lkb1, although dispensable for the acute down-regulation of mTOR in response to acute hypoxia, play important roles in maintaining mTOR inhibition with prolonged hypoxia. Indeed, AMPK appears to be activated in HeLa cells with prolonged hypoxia, although this activation seems to be Lkb1 independent (Supplementary Fig. 3).

Pathways that regulate Tsc1/Tsc2 function are disrupted in cancer (Brugarolas and Kaelin 2004). Consequently, Redd 1 might also function as a tumor suppressor and be mutated in human cancers. As Redd1 is involved in hypoxic signaling, but not growth factor signaling, the discovery of Redd1 mutations in tumors would emphasize the importance of hypoxia in the physiological regulation of Tsc1/Tsc2 tumor suppressor function.

Redd1 is induced by DNA damage, heat shock, and the p53 family member p63, in addition to being induced by hypoxia. This suggests that Redd1 may play a role in the regulation of mTOR by other forms of cellular stress. DNA damage can down-regulate mTOR signaling (Tee et al. 2003) but it is not known whether this requires Tsc1/Tsc2 and Redd1. Since overexpression of Redd2 can also down-regulate mTOR, situations that induce Redd2 expression would also predictably lead to the down-regulation of the mTOR pathway. Both Redd1 and Redd2 are expressed during development (Ellisen et al. 2002). However, while inactivation of the Drosophila Redd orthologs does not affect survival during normal development (Reiling and Hafen 2004), it diminishes survival under conditions of hypoxia and starvation, suggesting that Redd1 and Redd2 might both regulate cell growth in response to a variety of stresses.

\section{Materials and methods}

\section{Reagents}

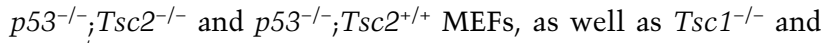
$\mathrm{Tsc}^{+/+} 3 \mathrm{~T} 3$ mouse cells, were a gift from H. Onda and D.J. Kwiatkowski (Brigham and Women's Hospital, Harvard Medical School, Boston, MA); $L k b 1^{+/+}$and $L k b 1^{-/-}$MEFs were a gift from N. Bardeesy and R. DePinho (Dana-Farber Cancer Institute, Harvard Medical School, Boston, MA); pcDNA3/FLAGHA-Tsc2 was a gift from F. Vazquez (Johns Hopkins University, Baltimore, MD); and pRK7/HA-S6K1 (rat $\alpha \mathrm{II}$ isoform) was a gift from J. Blenis (Harvard Medical School, Boston, MA). The Hif antibody, which recognizes both Hif- $1 \alpha$ and Hif- $2 \alpha$ (J. Brugarolas, unpubl.) was a gift from J. Pouyssegur (Institute of Signaling, Developmental Biology and Cancer Research, Nice, France) (Richard et al. 1999). The AMPK antibody was described previously (Hamilton et al. 2001). The remaining antibodies were purchased from the following vendors: Sigma: Tubulin- $\alpha$ (clone B-5-1-2); Santa Cruz: Tsc2 (C20), HA (Y11); Covance: HA
(HA11); or Cell Signaling: phosphorylated S6 S235/236, phosphorylated ACC S79, phosphorylated AMPK T172, p70 S6K, 4E-BP1, and eIF-4E. 7-Methyl GTP-sepharose was from Amersham. Rapamycin (Calbiochem, cat. 553210) was used at $25 \mathrm{nM}$ from a $25-\mu \mathrm{M}$ stock solution in methanol. AICAR /Calbiochem, cat. 123040 ) was used at $1 \mathrm{mM}$ from a $100-\mathrm{mM}$ stock solution in water. AMPKi, compound C (Merck) was used at $5 \mu \mathrm{M}$ from a $10-\mathrm{mM}$ stock in DMSO. Actinomycin D (Sigma) was used at 5 $\mu \mathrm{g} / \mathrm{mL}$ from a $0.5-\mathrm{mg} / \mathrm{mL}$ stock in water. Tetracycline (Sigma) was used at $10 \mu \mathrm{g} / \mathrm{mL}$ from a $10 \mathrm{mg} / \mathrm{mL}$ stock in water.

\section{Cloning}

Human Tsc2 cDNA (exon 31 deletion isoform) was excised from pcDNA3/FLAG-HA-Tsc2 with BamH1 and XbaI. The XbaI site was blunt ended with Klenow prior to insert excision. The insert was ligated into pBabe-puro/HA previously cut with BamH1 and SnaBI to make pBabe/HA-Tsc2, which was confirmed by restriction digestion and cDNA end-sequencing. Redd 1 and Redd 2 cDNAs were isolated by PCR from primary human and murine fibroblasts, respectively, cloned into the pcDNA3 expression vector, and sequence verified. Redd1dC carries a deletion of amino acids 96-153 and was made by overlap PCR.

\section{Tissue culture}

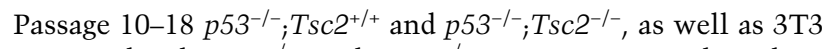
immortalized $\mathrm{Tsc1}^{+/+}$and $T s \mathrm{~T}^{-/-} \mathrm{MEFs}$, were cultured in DMEM with high glucose (Invitrogen), 10\% heat-inactivated FBS (Hyclone), and 1\% P/S (Gibco), and exposed to hypoxia (In vivo2; Biotrace) where indicated ( $1 \%$ oxygen, $10 \%$ carbon dioxide at $37^{\circ} \mathrm{C}$ ). Growth curves were determined by counting cells in triplicate wells sequentially for $4 \mathrm{~d}$. Cell death was determined by scoring trypan blue positivity after staining with $0.4 \%$ trypan blue (Sigma). Lbk1 $1^{-1-}$ and Redd1 $1^{-/-}$MEFs (and respective littermate controls) were used at an early passage $(<10)$. For hypoxia experiments, $L b k 1^{-/-}$and Redd1 $1^{-/-}$MEFs were cultured in MEM $\alpha$ (Invitrogen) or DMEM, with $2 \%$ FBS and $1 \% \mathrm{P} / \mathrm{S}$. The Tet-inducible Redd 1 line was created by transfecting the T-RExU2OS founder line (Invitrogen) with pcDNA4/TO (Invitrogen) carrying a Redd 1 cDNA followed by clonal selection. Cells were transfected with siRNA, split $48 \mathrm{~h}$ later, and treated with tetracycline for $24 \mathrm{~h}$ prior to harvest.

\section{Retroviral transduction}

Phoenix amphotropic cells were transfected with empty pBabe/ HA, or pBabe/HA-Tsc2 using Lipofectamine Plus (Invitrogen) following manufacturer's recommendations. Supernatant was collected at several intervals $36 \mathrm{~h}$ after transfection and used to infect exponentially growing Tsc2 ${ }^{-/-}$MEFs (passage 10) in the presence of polybrene $(4 \mu \mathrm{g} / \mathrm{mL})$. Cells were selected in $2 \mu \mathrm{g} / \mathrm{mL}$ puromycin for $6 \mathrm{~d}$ and utilized for experiments for two additional passages.

\section{SiRNA transfections}

siRNA transfections were as previously described (Brugarolas et al. 2003). For experiments involving transfection of both siRNA and plasmids, HeLa cells were seeded at very low density and transfected with siRNA using Oligofectamine (Invitrogen) per manufacturer's recommendations except that the amount of siRNA was tripled. Approximately $48 \mathrm{~h}$ later, when $\sim 80 \%$ confluent, the cells were transfected with plasmid DNA using Lipofectamine Plus (Invitrogen) per the manufacturer's recommendations. SiRNA sequences: Sc (5'-CAAUGAGUAACAAU CCAUUGA-3'); Tsc2 (a) (5'-CAAUGAGUCACAGUCCUUU 
GA-3') (Inoki et al. 2002); Tsc2 (b) (5'-AAAGUUCACCUACU GCUGGCA-3').

\section{Western blot and immunoprecipitation assays}

Western blot analysis was as previously described (Brugarolas et al. 2003). For immunoprecipitations, cells were lysed in IP buffer $(50 \mathrm{mM}$ Tris $\mathrm{HCl}$ at $\mathrm{pH} 7.5,150 \mathrm{mM} \mathrm{NaCl}$, and $0.5 \%$ Igepal CA-630 [Sigma] supplemented with Complete Mini [Roche] and phosphatase inhibitors [Calbiochem]) for $20 \mathrm{~min}$ at $4{ }^{\circ} \mathrm{C}$. The lysates were precleared with protein A sepharose (Amersham), normalized for protein content, and immunoprecipitated with 2-3 $\mu$ g anti-HA (Y11)/mg of protein overnight at $4^{\circ} \mathrm{C}$. Immunoprecipitates were recovered on Protein A sepharose, washed three times with IP buffer, eluted with hot SDS sample buffer, and analyzed by SDS PAGE.

\section{${ }^{7}$ mGTP binding assays}

For ${ }^{7} \mathrm{mGTP}$ binding assays, MEFs were lysed in IP buffer. The lysates were precleared by centrifugation, normalized for protein content, and incubated with ${ }^{7} \mathrm{mGTP}$-sepharose for $2 \mathrm{~h}$ at $4^{\circ} \mathrm{C}$. The sepharose was recovered by centrifugation, washed with IP buffer four times, and boiled in $1 \times$ SDS loading buffer. Eluted proteins were analyzed by SDS-PAGE on a $12 \%$ gel.

\section{Kinase assay}

AMPK kinase assays were as described with minor modifications (Hamilton et al. 2001). Briefly, exponentially growing $\mathrm{Tsc}^{+/+} \mathrm{MEFs}$ were lysed in IP buffer. Lysates were normalized for protein content prior to immunoprecipitation with AMPK antibody (Hamilton et al. 2001) or rabbit serum IgG under antibody excess conditions. Immunoprecipitates were incubated with ATP $\gamma{ }^{32} \mathrm{P}$ (NEN) in the presence or absence of SAMS peptide for $25 \mathrm{~min}$ at $30^{\circ} \mathrm{C}$. No AMP was added. Reactions were spotted onto p81 paper and thoroughly washed with $0.75 \%$ phosphoric acid and acetone. Radioactivity of the filters was determined using a scintillation counter (Beckman LS 6500).

\section{Northern blot}

Total RNA was prepared from primary MEFs using RNA STAT60 (Tel-Test). Ten micrograms total RNA per lane was electrophoresed through a $6 \%$ formaldehyde $/ 1 \%$ agarose gel, transferred to Hybond-N nylon membrane (Amersham), and hybridized to ${ }^{32} \mathrm{P}$-labeled murine Redd1, Redd2, and GAPDH cDNA probes.

\section{Animal hypoxia experiments}

C57BL/6 mice 2-4 mo old were placed in the hypoxia chamber with abundant food and drink. Oxygen concentration was slowly decreased from $21 \%$ to $6 \%$ over $1 \mathrm{~h} . \mathrm{CO}_{2}$ was $1 \%$ and temperature $25^{\circ} \mathrm{C}$.

\section{Acknowledgments}

We thank J. Cifuni, R. Pietravalle, and A. Sofer for technical assistance; H. Onda and D.J. Kwiatkowski for $p 53^{-/-} ; T_{s c 2^{-/}}$and p53 ${ }^{-I^{-}} ; \mathrm{Tsc2}^{+/+}$, as well as immortalized $\mathrm{Tsc1}^{+/+}$and $\mathrm{Tsc1}^{-{ }^{-}}$ MEFs; J. Pouyssegur for Hif antibody; F. Vazquez for Tsc2 expression vector; J. Blenis for S6K vector; and G. Zhou (Merck) for compound C. This work was supported by the Claudia Adams Barr Foundation (J.B.), the Mittleman Foundation (J.B.), the
DOD (J.B. and W.G.K.), and NIH DK35712 (L.A.W.). W.G.K. is an HHMI Investigator. Redd1 reagents described in this paper should be requested from L.W.E.

\section{References}

Arsham, A.M., Howell, J.J., and Simon, M.C. 2003. A novel hypoxia-inducible factor-independent hypoxic response regulating mammalian target of rapamycin and its targets. $J$. Biol. Chem. 278: 29655-29660.

Brugarolas, J. and Kaelin, W.G. 2004. Dysregulation of HIF and VEGF is a unifying feature of the familial hamartoma syndromes. Cancer Cell 6: 7-10.

Brugarolas, J., Vazquez, F., Reddy, A., Sellers, W.R., and Kaelin, W.G. 2003. TSC2 regulates VEGF through mTOR-dependent and -independent pathways. Cancer Cell 4: 147-156.

Cantley, L.C. 2002. The phosphoinositide 3-kinase pathway. Science 296: 1655-1657.

Carling, D. 2004. The AMP-activated protein kinase cascade-A unifying system for energy control. Trends Biochem. Sci. 29: 18-24.

Carsillo, T., Astrinidis, A., and Henske, E.P. 2000. Mutations in the tuberous sclerosis complex gene TSC2 are a cause of sporadic lymphangioleiomyomatosis. Proc. Natl. Acad. Sci. 11: 6085-6090.

Castro, A.F., Rebhun, J.F., Clark, G.G., and Quilliam, L.A. 2003. Rheb binds tuberous sclerosis complex 2 (TSC2) and promotes S6 kinase activation in a rapamycin- and farnesylation-dependent manner. J. Biol. Chem. 278: 32493-32496.

Cheadle, J.P., Reeve, M.P., Sampson, J.R., and Kwiatkowski, D.J. 2000. Molecular genetic advances in tuberous sclerosis. Hum. Genet. 107: 97-114.

Corradetti, M.N., Inoki, K., Bardeesy, N., DePinho, R.A., and Guan, K.-L. 2004. Regulation of the TSC pathway by LKB1: Evidence of a molecular link between tuberous sclerosis complex and Peutz-Jeghers syndrome. Genes \& Dev. 18: 1533-1538.

Cuaz-Perolin, C., Furman, C., Larigauderie, G., Legedz, L., Lasselin, C., Copin, C., Jaye, M., Searfoss, G., Yu, K.T., Duverger, N., et al. 2004. REDD2 gene is upregulated by modified LDL or hypoxia and mediates human macrophages cell death. Arterioscler. Thromb. Vasc. Biol. 24: 1830-1835.

Dan, H.C., Sun, M., Yang, L., Feldman, R.I., Sui, X.M., Ou, C.C., Nellist, M., Yeung, R.S., Halley, D.J., Nicosia, S.V., et al. 2002. Phosphatidylinositol 3-kinase/Akt pathway regulates tuberous sclerosis tumor suppressor complex by phosphorylation of tuberin. J. Biol. Chem. 277: 35364-35370.

Dufner, A. and Thomas, G. 1999. Ribosomal S6 kinase signaling and the control of translation. Exp. Cell Res. 253: 100-109.

El-Hashemite, N., Walker, V., Zhang, H., and Kwiatkowski, D.J. 2003. Loss of Tsc1 or Tsc2 induces vascular endothelial growth factor production through mammalian target of rapamycin. Cancer Res. 63: 5173-5177.

Ellisen, L.W., Ramsayer, K.D., Johannessen, C.M., Yang, A., Beppu, H., Minda, K., Oliner, J.D., McKeon, F., and Haber, D.A. 2002. REDD1, a developmentally regulated transcriptional target of p63 and p53, links p63 to regulation of reactive oxygen species. Mol. Cell 10: 995-1005.

Fingar, D.C. and Blenis, J. 2004. Target of rapamycin (TOR): An integrator of nutrient and growth factor signals and coordinator of cell growth and cell cycle progression. Oncogene 23: 3151-3171.

Gao, X. and Pan, D. 2001. TSC1 and TSC2 tumor suppressors antagonize insulin signaling in cell growth. Genes \& Dev. 15: $1383-1392$. 
Gao, X., Zhang, Y., Arrazola, P., Hino, O., Kobayashi, T., Yeung, R.S., Ru, B., and Pan, D. 2002. Tsc tumour suppressor proteins antagonize amino-acid-TOR signalling. Nat. Cell Biol. 4: 699-704.

Garami, A., Zwartkruis, F.J., Nobukuni, T., Joaquin, M., Roccio, M., Stocker, H., Kozma, S.C., Hafen, E., Bos, J.L., and Thomas, G. 2003. Insulin activation of Rheb, a mediator of mTOR/S6K/4E-BP signaling, is inhibited by TSC1 and 2 . Mol. Cell 11: 1457-1466.

Gingras, A.C., Raught, B., and Sonenberg, N. 2001. Regulation of translation initiation by $\mathrm{FRAP} / \mathrm{mTOR}$. Genes \& Dev. 15: $807-826$.

Hamilton, S.R., Stapleton, D., O'Donnell Jr., J.B., Kung, J.T., Dalal, S.R., Kemp, B.E., and Witters, L.A. 2001. An activating mutation in the $\gamma 1$ subunit of the AMP-activated protein kinase. FEBS Lett. 500: 163-168.

Hawley, S.A., Boudeau, J., Reid, J.L., Mustard, K.L., Udd, L., Makela, T.P., Alessi, D.R., and Hardie, D.G. 2003. Complexes between the LKB1 tumor suppressor, STRAD $\alpha / \beta$ and $\mathrm{MO} 25 \alpha / \beta$ are upstream kinases in the AMP-activated protein kinase cascade. J. Biol. 2: 28.

Hudson, C.C., Liu, M., Chiang, G.G., Otterness, D.M., Loomis, D.C., Kaper, F., Giaccia, A.J., and Abraham, R.T. 2002. Regulation of hypoxia-inducible factor $1 \alpha$ expression and function by the mammalian target of rapamycin. Mol. Cell. Biol. 22: 7004-7014.

Inoki, K., Li, Y., Zhu, T., Wu, J., and Guan, K.L. 2002. TSC2 is phosphorylated and inhibited by Akt and suppresses mTOR signalling. Nat. Cell Biol. 4: 648-657.

Inoki, K., Li, Y., Xu, T., and Guan, K.L. 2003a. Rheb GTPase is a direct target of TSC2 GAP activity and regulates mTOR signaling. Genes \& Dev. 17: 1829-1834.

Inoki, K., Zhu, T., and Guan, K.L. 2003b. TSC2 mediates cellular energy response to control cell growth and survival. Cell 115: $577-590$.

Jaeschke, A., Hartkamp, J., Saitoh, M., Roworth, W., Nobukuni, T., Hodges, A., Sampson, J., Thomas, G., and Lamb, R. 2002. Tuberous sclerosis complex tumor suppressor-mediated S6 kinase inhibition by phosphatidylinositide-3-OH kinase is mTOR independent. J. Cell Biol. 159: 217-224.

Kaelin Jr., W.G. 2002. Molecular basis of the VHL hereditary cancer syndrome. Nat. Rev. Cancer 2: 673-682.

Karbowniczek, M., Cash, T., Cheung, M., Robertson, G.P., Astrinidis, A., and Henske, E.P. 2004. Regulation of B-Raf kinase activity by tuberin and Rheb is mTOR independent. $J$. Biol. Chem. 279: 29930-29937.

Kimura, N., Tokunaga, C., Dalal, S., Richardson, C., Yoshino, K., Hara, K., Kemp, B.E., Witters, L.A., Mimura, O., and Yonezawa, K. 2003. A possible linkage between AMP-activated protein kinase (AMPK) and mammalian target of rapamycin (mTOR) signalling pathway. Genes Cells 8: 65-79.

Kwiatkowski, D.J., Zhang, H., Bandura, J.L., Heiberger, K.M., Glogauer, M., el-Hashemite, N., and Onda, H. 2002. A mouse model of TSC1 reveals sex-dependent lethality from liver hemangiomas, and up-regulation of p70S6 kinase activity in Tsc1 null cells. Hum. Mol. Genet. 11: 525-534.

Liu, M.Y., Poellinger, L., and Walker, C.L. 2003. Up-regulation of hypoxia-inducible factor $2 \alpha$ in renal cell carcinoma associated with loss of Tsc- 2 tumor suppressor gene. Cancer Res. 63: $2675-2680$.

Manning, B.D., Tee, A.R., Logsdon, M.N., Blenis, J., and Cantley, L.C. 2002. Identification of the tuberous sclerosis complex-2 tumor suppressor gene product tuberin as a target of the phosphoinositide 3-kinase/akt pathway. Mol. Cell 10: 151-162.

Nguyen-Vu, P.A., Fackler, I., Rust, A., DeClue, J.E., Sander,
C.A., Volkenandt, M., Flaig, M., Yeung, R.S., and Wienecke, R. 2001. Loss of tuberin, the tuberous-sclerosis-complex-2 gene product is associated with angiogenesis. J. Cutan. Pathol. 28: 470-475.

Pende, M., Um, S.H., Mieulet, V., Sticker, M., Goss, V.L., Mestan, J., Mueller, M., Fumagalli, S., Kozma, S.C., and Thomas, G. 2004. S6K1 (-/-)/S6K2 (-/-) mice exhibit perinatal lethality and rapamycin-sensitive $5^{\prime}$-terminal oligopyrimidine mRNA translation and reveal a mitogen-activated protein kinase-dependent S6 kinase pathway. Mol. Cell. Biol. 24: 3112-3124.

Potter, C.J., Huang, H., and Xu, T. 2001. Drosophila Tsc1 functions with Tsc2 to antagonize insulin signaling in regulating cell growth, cell proliferation, and organ size. Cell 105: 357368.

Potter, C.J., Pedraza, L.G., and Xu, T. 2002. Akt regulates growth by directly phosphorylating Tsc2. Nat. Cell Biol. 4: 658-665.

Reiling, J.H. and Hafen, E. 2004. The hypoxia-induced paralogs Scylla and Charybdis inhibit growth by down-regulating S6K activity upstream of TSC in Drosophila. Genes \& Dev. (this issue).

Rennebeck, G., Kleymenova, E.V., Anderson, R., Yeung, R.S., Artzt, K., and Walker, C.L. 1998. Loss of function of the tuberous sclerosis 2 tumor suppressor gene results in embryonic lethality characterized by disrupted neuroepithelial growth and development. Proc. Natl. Acad. Sci. 95: 1562915634.

Richard, D.E., Berra, E., Gothie, E., Roux, D., and Pouyssegur, J. 1999. p42/p44 mitogen-activated protein kinases phosphorylate hypoxia-inducible factor $1 \alpha$ (HIF-1 $\alpha)$ and enhance the transcriptional activity of HIF-1. J. Biol. Chem. 274: 3263132637.

Saucedo, L.J., Gao, X., Chiarelli, D.A., Li, L., Pan, D., and Edgar, B.A. 2003. Rheb promotes cell growth as a component of the insulin/TOR signalling network. Nat. Cell Biol. 5: 566-571.

Scavelli, C., Weber, E., Agliano, M., Cirulli, T., Nico, B., Vacca, A., and Ribatti, D. 2004. Lymphatics at the crossroads of angiogenesis and lymphangiogenesis. J. Anat. 204: 433-449.

Semenza, G.L. 2000. HIF-1 and human disease: One highly involved factor. Genes \& Dev. 14: 1983-1991.

Shaw, R.J., Bardeesy, N., Manning, B.D., Lopez, L., Kostmatka, M., DePinho, R.A., and Cantley, L.C. 2004a. The LKB1 tumor suppressor negatively regulates $\mathrm{mTOR}$ signaling. Cancer Cell 6: 91-99.

Shaw, R.J., Kosmatka, M., Bardeesy, N., Hurley, R.L., Witters, L.A., DePinho, R.A., and Cantley, L.C. 2004b. Inaugural article: The tumor suppressor LKB1 kinase directly activates AMP-activated kinase and regulates apoptosis in response to energy stress. Proc. Natl. Acad. Sci. 101: 3329-3335.

Shoshani, T., Faerman, A., Mett, I., Zelin, E., Tenne, T., Gorodin, S., Moshel, Y., Elbaz, S., Budanov, A., Chajut, A., et al. 2002. Identification of a novel hypoxia-inducible factor 1-responsive gene, RTP801, involved in apoptosis. Mol. Cell. Biol. 22: 2283-2293.

Stocker, H., Radimerski, T., Schindelholz, B., Wittwer, F., Belawat, P., Daram, P., Breuer, S., Thomas, G., and Hafen, E. 2003. Rheb is an essential regulator of $S 6 \mathrm{~K}$ in controlling cell growth in Drosophila. Nat. Cell Biol. 5: 559-566.

Tapon, N., Ito, N., Dickson, B.J., Treisman, J.E., and Hariharan, I.K. 2001. The Drosophila tuberous sclerosis complex gene homologs restrict cell growth and cell proliferation. Cell 105: 345-355.

Tee, A.R., Manning, B.D., Roux, P.P., Cantley, L.C., and Blenis, J. 2003. Tuberous sclerosis complex gene products, Tuberin and Hamartin, control mTOR signaling by acting as a GT- 
Brugarolas et al.

Pase-activating protein complex toward Rheb. Curr. Biol. 13: 1259-1268.

Tiainen, M., Ylikorkala, A., and Makela, T.P. 1999. Growth suppression by Lkb1 is mediated by a G (1) cell cycle arrest. Proc. Natl. Acad. Sci. 96: 9248-9251.

van Slegtenhorst, M., Nellist, M., Nagelkerken, B., Cheadle, J., Snell, R., van den Ouweland, A., Reuser, A., Sampson, J., Halley, D., and van der Sluijs, P. 1998. Interaction between hamartin and tuberin, the TSC1 and TSC2 gene products. Hum. Mol. Genet. 7: 1053-1057.

Volarevic, S., Stewart, M.J., Ledermann, B., Zilberman, F., Terracciano, L., Montini, E., Grompe, M., Kozma, S.C., and Thomas, G. 2000. Proliferation, but not growth, blocked by conditional deletion of $40 \mathrm{~S}$ ribosomal protein S6. Science 288: 2045-2047.

Woods, A., Johnstone, S.R., Dickerson, K., Leiper, F.C., Fryer, L.G., Neumann, D., Schlattner, U., Wallimann, T., Carlson, M., and Carling, D. 2003. LKB1 is the upstream kinase in the AMP-activated protein kinase cascade. Curr. Biol. 13: 20042008.

Zhang, H., Cicchetti, G., Onda, H., Koon, H.B., Asrican, K., Bajraszewski, N., Vazquez, F., Carpenter, C.L., and Kwiatkowski, D.J. 2003. Loss of Tsc1/Tsc2 activates mTOR and disrupts PI3K-Akt signaling through downregulation of PDGFR. J. Clin. Invest. 112: 1223-1233.

Zhang, Y., Gao, X., Saucedo, L.J., Ru, B., Edgar, B.A., and Pan, D. 2003. Rheb is a direct target of the tuberous sclerosis tumour suppressor proteins. Nat. Cell Biol. 5: 578-581. 


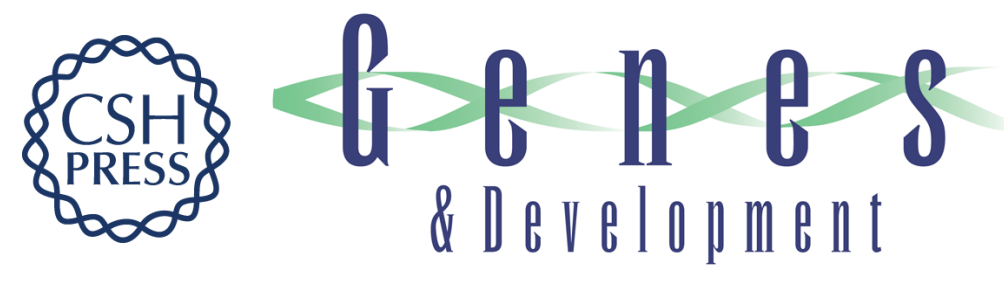

\section{Regulation of mTOR function in response to hypoxia by REDD1 and the TSC1/TSC2 tumor suppressor complex}

James Brugarolas, Kui Lei, Rebecca L. Hurley, et al.

Genes Dev. 2004, 18:

Access the most recent version at doi:10.1101/gad.1256804

\section{Supplemental http://genesdev.cshlp.org/content/suppl/2004/11/16/gad.1256804.DC1 Material}

References This article cites 52 articles, 22 of which can be accessed free at: http://genesdev.cshlp.org/content/18/23/2893.full.html\#ref-list-1

\section{License}

Email Alerting

Receive free email alerts when new articles cite this article - sign up in the box at the top Service

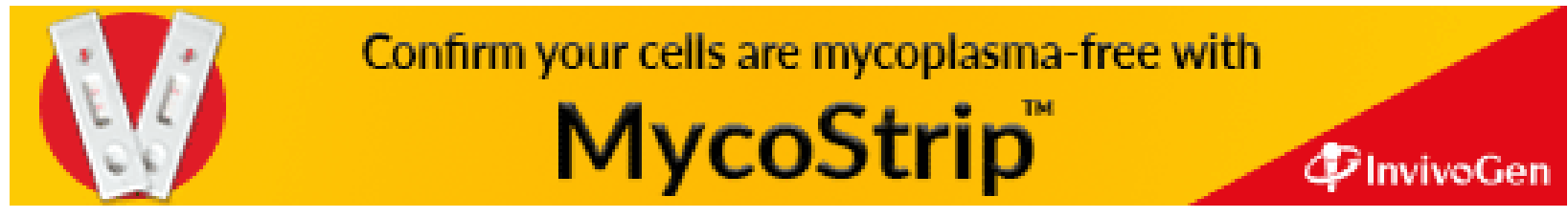

